\title{
Study Design in Dementia Drug Trials
}

\author{
Chris MacKnight
}

\begin{abstract}
A great deal of progress has been made in the management of Alzheimer's disease and other dementias over the past 25 years. Much remains to be achieved, however. This article discusses some of the issues surrounding study design. In the absence of an accepted biological marker of progression, it is unlikely that a novel study design, such as randomized start or withdrawal, in itself could provide convincing evidence of disease modification. Biological markers will also be crucial in the development of therapies aimed at specific processes, and of immunotherapies.
\end{abstract}

RÉSUMÉ: Plan d'étude pour les essais thérapeutiques sur la démence. Le traitement de la maladie d'Alzheimer et des autres démences s'est beaucoup amélioré depuis 25 ans. Cependant, il reste beaucoup à faire. Cet article discute des problèmes relatifs au plan d'étude. Comme il n'existe pas de marqueur biologique accepté pour évaluer la progression de la maladie il est peu probable qu'un plan d'étude novateur tel un début randomisé ou un retrait de la médication anti-démence pourra fournir des données convaincantes que l'évolution de la maladie a été modifiée. Des marqueurs biologiques seront également cruciaux pour le développement de traitements ciblant des processus spécifiques et pour le développement d'immunothérapies.

Can. J. Neurol. Sci. 2007; 34: Suppl. 1 - S19-22

Despite 25 years of effort in developing treatments for Alzheimer's disease and other dementias, the available agents are not widely used. Provincial formularies in Canada have been slow to accept these agents, and as of 2005 several have never approved them as an insured benefit. The National Institute for Clinical Excellence in the United Kingdom has had significant reservations about their efficacy. ${ }^{1,2}$ Are these concerns because the treatments truly provide little benefit to patients, or could it be that relevance of the study results to clinical practice and day to day life is difficult to assess? Could the studies as designed, and the outcome measures chosen, be a barrier to the use of these drugs? The purpose of this brief paper is to review the current state of clinical trials in dementia, highlight some of the areas where we may have gone wrong, and make a few suggestions for future discussions.

Studies in older adults are more difficult to conduct than in younger adults, but this shouldn't stop clinical trialists from trying. ${ }^{3}$ The difficulties include comorbidities, concomitant medications, sensory deficits, and practical matters, such as transportation. Furthermore, sample sizes need to be large because of projected drop-out and increased variability of the outcome measures (as older adults are more heterogeneous than younger ones). On the other hand, older adults may be more compliant with study procedures, especially if the clinical-trial staff take an individualized "case-management" approach.
Alzheimer's disease (AD) also has unique difficulties; for example, the maximum tolerated dose of potential agents may be up to $100 \%$ higher in patients than in healthy controls. ${ }^{4}$

What is the point in doing clinical trials? To demonstrate that the study agent is different from or equivalent to another treatment, or better than no treatment, in terms of a clinical outcome in people who reliably have the condition in question. ${ }^{5}$ This will, of course, be different in prevention trials. Both efficacy and tolerability need to be considered, with economic effects also of importance.

The traditional study design has been a parallel-group, placebo-controlled randomized trial, typically lasting six months. Most have included repeated measures of various cognitive, global, functional, and behavioural tests, with the primary outcome being difference at six months, with a last

From the Division of Geriatric Medicine, Dalhousie University, Halifax, NS, Canada. ReCEIVED OCTOBER 7, 2005. ACCEPTED IN FINAL FORM MARCH 21, 2006. Reprint requests to: Chris MacKnight, Division of Geriatric Medicine, Dalhousie University, 5955 Veterans' Memorial Lane, Halifax, Nova Scotia, B3H 2E1, Canada. 
observation carried forward analysis. The American Food and Drug Administration was perceived as requiring the Alzheimer's Disease Assessment Scale (cognitive subscale) (ADAS-cog) and Clinician's Interview-based Impression of Change (CIBIC) as the primary outcome measures in these trials and does require at least two randomized, double-blind, placebo-controlled studies of 3-6 months duration. ${ }^{6}$

Unfortunately, the traditional outcome measures used in these trials, such as the ADAS-cog, are meaningless to patients, caregivers, primary care personnel, and funders. The National Institute for Clinical Excellence in the United Kingdom recommended withdrawing the agents in 2005, because of the lack of clinically meaningful outcomes in the available studies (they've since reconsidered). ${ }^{1,2}$ Some investigators are developing instruments where patients, caregivers and clinicians can choose and monitor their own, clinically relevant goals. ${ }^{7,8}$ Even when instruments are familiar, it is difficult to interpret the importance of the results. ${ }^{9}$ The Last Observation Carried Forward analysis is flawed for a progressive disease when there are a large number of drop-outs, with different trends for dropout in the treatment and control arms. Careful consideration of the subject sample, retention, and outcomes are necessary to ensure the successful completion of trials of any design. There are proposals to expedite drug development through careful study design and conduct. ${ }^{4}$ Adaptive designs, where early study results can lead to modification of later study methods and goals, are also being considered.

\section{DESIGN ISSUES}

Most new agents will be developed as either add-on therapy or with an active control. One danger with an add-on design is that an unsuspected interaction may falsely suggest that the study drug is ineffective. Active-control designs will need to have larger samples, as the difference between groups may be smaller. For medications meant to be cognitive enhancers, a reasonable approach for early Phase III studies might be a single-blind runin, with early responders randomized in an add-on trial and probable non-responders discontinued (or enrolled in an uncontrolled open-label study to collect safety data). There are concerns with these enrichment strategies, particularly with carry-over effects into the double-blind phase. ${ }^{5}$ Unfortunately, these designs will mean that most new agents will be approved as add-on therapy only, not as initial monotherapy.

Other enrichment strategies could be used based on clinical characteristics or, perhaps, markers such as apolipoprotein E (apoE) alleles. ${ }^{10,11}$ Unfortunately, these designs will affect the generalizability, especially with the suggestion that apoE may also affect response to some agents. ${ }^{12}$

Time-to-event studies will be seen more often, with changes in stage or function as the main outcomes. ${ }^{13}$ Death and nursing home placement are poor primary outcomes because of competing risks and extrinsic influences. This was the design in the AD2000 trial, which used time to placement as its primary outcome. ${ }^{14}$ Nursing home placement is affected not only by the patient's disease, but also by availability of nursing home beds, community supports, and the presence and health of informal caregivers.

In general, a repeated cross-over design would not be appropriate in dementia, because in a progressive illness the intervals late in the study would not be comparable to those early in the study. Also, historical controls are generally inappropriate, given the rapid changes in overall management of these patients and the services available.

\section{Demonstration Of Symptomatic VS. Disease-Modifying EFFECTS}

Delaying the time until major clinical endpoints in a parallelgroup study is not, in itself, evidence of disease modification. The two designs suggested to demonstrate this effect are randomized withdrawal and randomized start trials. ${ }^{6,15}$

In the randomized withdrawal design, subjects originally randomized to the active treatment arm are randomized to a blinded withdrawal of treatment. If the withdrawn group does not decline to a similar level as the original control arm, then disease modification is implied. There are feasibility and potentially ethical problems with this design, particularly with stopping a potentially effective agent in a responding study subject. Other threats are the (often unknown) duration of carryover of the treatment effect, the presence of withdrawal effects that could un-blind subjects or investigators, and the assumption that drop-outs during the study will not lead to group imbalance by the point of withdrawal.

In the randomized start trial, some subjects are randomized to a delayed start of active treatment. If they do not achieve the same benefit as the early active treatment group, it is assumed that the active agent is disease-modifying. This assumes that response to an agent is not stage-specific and, again, that dropouts will not lead to imbalance between the groups by the time of the delayed start. ${ }^{16}$

Should we not bother trying to demonstrate diseasemodification with design-based methods? Should the emphasis be on the development of valid, reliable and responsive biological markers? Surrogate markers do carry dangers, as they may not translate into clinical benefits. ${ }^{17}$ The demonstration of disease modification remains an elusive goal and will likely continue to do so until an accepted biological marker, with a strong link to important clinical outcomes, becomes available.

\section{Prevention And Progression Trials}

These will, of necessity, be relatively long and costly. Costs can be controlled through any of: enrollment of a high-risk population; extensive use of biological rather than clinical markers; or a pared-down clinical assessment. ${ }^{18}$ Outcomes used will need to be sensitive to small changes in mild disease. Formulas are available for estimating sample size in such trials. ${ }^{19}$ One-year trials using time to loss of function or decline in stage have been successful, so progression trials will likely be feasible..$^{20,21}$

Prevention trials will need to be very large, unless a high-risk population is chosen. ${ }^{18}$ The agents studied will need to be very safe, and data collection will need to be acceptable for large amounts of people over long periods, yet also have very small measurement error. Data collection for safety purposes may need to continue long after the clinical study is finished and reported. Drop-out rates, and endpoints due to competing risks, will also be high, so the quality of clinical data will need to be high. Adherence to protocol will be difficult to maintain but, of course, 
simpler protocols will more often be followed correctly. Factorial designs may maximize the efficiency in these trials, as will nesting these studies in other large research programs (as was done with the Syst-Eur trial, among others). ${ }^{22}$

\section{OTHER ISSUES}

Outcomes: The clinical outcomes used in most antidementia trials are meaningless to the end-users of the products. The outcome measures chosen need to be more rational, though accepted by regulatory authorities, which requires careful clinimetric development. Time-to-clinical event studies will be an improvement. Other fields routinely use non-clinical outcomes in Phase III trials, such as degree of joint narrowing in rheumatology and tumour size or percent abnormal cells in oncology. The development of biological markers for use in antidementia trials remains a research priority.

Population: Most antidementia trials, unfortunately, target a population quite different from that seen clinically. ${ }^{23-26}$ Sponsors should try to make the population as similar to those who will be using the drug as possible, while, in my view, regulatory agencies should ignore trials with highly selected populations (other than for proof of principle studies).

Analysis: Complete outcome data on all randomized subjects is the goal for an unbiased analysis. Studies need to make an effort to follow patients who stop a study drug. While it may be easier said than done, simple, unobtrusive primary outcome measures would be a step forward. This would do away with the need for the flawed LOCF analyses and allow true Intention-to-Treat (ITT) analyses. Other options are the use of retrieved dropouts and sensitivity analyses. ${ }^{27}$

\section{Design For Trials Of Agents Aimed At Biological Processes}

Traditional Phase I and II goals, such as toxicity and response, need to be supplemented when investigating agents aimed at specific biological processes. ${ }^{28}$ Biological endpoints should also be used. Unfortunately, many of the targets of interest in AD are accessible only in the brain. Accessible peripheral or imaging markers and outcomes need to be developed and validated for use in Phase I and II trials. ${ }^{29}$ For example, if an agent were developed to reduce deposition of beta-amyloid in the brain, then biological or imaging markers of this process would be an appropriate Phase II primary outcome. Also, in Phase I trials, rather than looking for the maximal tolerated dose, the trialists should look for the optimal biological dose (as higher doses may not necessarily have the best biological effect). It is possible for the maximal tolerated dose (which is the target in traditional drug development) to be less effective than the optimal biological dose.

In Phase III trials, the traditional cognitive and global outcomes are less relevant to agents that hope to slow or stop the disease's progression, or even reverse the disease, as many of these outcome measures are not designed to measure improvement. ${ }^{30}$ Such trials will often need to use time to a particular endpoint, which will add to the length, size, and cost of the study. What defines significant slowing is also unclear. A method to increase the efficiency of these trials is to use a twostage design, where a marker of biological response is measured early in the study and non-responders are then discontinued. ${ }^{28}$ If a control arm is required, the responders can be randomized to continue or discontinue. For the most part, historical controls should be avoided, especially in a disease such as AD, where much can be gained from psychosocial support, the nature and availability of which is changing rapidly, and also where new strategies for treating comorbidities may affect the disease.

\section{DESIGN FOR IIMMUNOTHERAPY TRIALS}

Immunotherapy development is particularly challenging. ${ }^{31}$ Maximum-tolerated dose is less applicable, so many of the traditional Phase I activities are not necessary. Although there seems to be a belief that most vaccines are inherently safe, they can be toxic, but this will often not be found until the Phase II/III stages. Various delivery agents and adjuvants will affect the response in humans differently than in animals, so much of the usual preclinical studies have to be done in humans. Given recent experience in $\mathrm{AD}$, this will need to proceed with caution. ${ }^{32}$

The goal of the Phase I trials will be to show a biologic response to the agent. It may be necessary to do Phase II trials to find the minimally active dose, but this is often not feasible. Two-stage trials have been designed, where a small number of patients are enrolled, and, if a pre-specified number of responses is not seen, the agent/dose is declared inactive; if more than that number of responses is seen, then accrual continues and a larger study is done to demonstrate efficacy. ${ }^{31}$ A control group isn't required. These are simplest if done with a biological outcome but more convincing with a clinical outcome. Given that AD is, for the most part, slowly progressive, this design will be harder to implement than in the cancer trials where it has mostly been used. There are also "Phase 2.5" trials, which are randomized but use biological outcomes rather than clinical ones - in the drug development process these are probably most applicable to rapidly progressive diseases. Traditional Phase III trials would eventually be necessary.

\section{Phase IV Trials}

The public perceives that drug development does not pay enough attention to safety. The development of rigorous, structured Phase IV studies will go a long way in identifying safety issues and reassuring the public (if no safety issues are present, of course). These studies will be best accepted if conducted by investigators independent of both the company marketing the drug and regulatory agencies.

\section{SUMMARY}

We are moving into a new phase of antidementia drug development. Although progress has been rapid, and there are many opportunities in the near future, study design and conduct is becoming more difficult. The development of acceptable biological outcomes for use in early Phase II studies, to be followed by simple, meaningful clinical outcomes in late Phase II and III, are important next steps.

\section{DECLARATION}

Dr. MacKnight is supported by a New Investigator Award from the Canadian Institutes of Health Research. 
Dr. MacKnight has received grants and honoraria from Janssen-Ortho Inc., Lundbeck Canada, Myriad Pharmaceuticals, Neurochem Inc., Novartis Canada, Pfizer Canada, and Voyager Pharmaceuticals.

\section{REFERENCES}

1. Kmietowicz Z. NICE proposes to withdraw Alzheimer's drugs from NHS. BMJ. 2005;330:495.

2. Mayor S. NICE recommends drugs for moderate Alzheimer's disease. BMJ. 2006;332:195.

3. Applegate WB, Curb JD. Designing and executing randomized clinical trials involving elderly persons. J Am Geriatr Soc. 1990;38:943-50.

4. Anand R. Barriers to Alzheimer's disease drug discovery and drug development in the pharmaceutical industry. Alzheimer Dis Assoc Disord. 2002;16 Suppl 1:S33-9.

5. Leber PD, Davis CS. Threats to validity of clinical trials employing enrichment strategies for sample selection. Controlled Clin Trials. 1998;19:178-87.

6. Mani RB. The evaluation of disease-modifying therapies in Alzheimer's disease: a regulatory viewpoint. Stat Med. 2004;23:305-14.

7. Rockwood K, Graham JE, Fay S for the ACADIE Investigators. Goal setting and attainment in Alzheimer's disease patients treated with donepezil. J Neurol Neurosurg Psychiatry. 2002;73:500-7.

8. Rockwood K, Fay S, Song XW, MacKnight C, Gorman M on behalf of the Video-imaging Synthesis of Treating Alzheimer's disease (VISTA) investigators. Attainment of treatment goals by people with Alzheimer's disease receiving galantamine: a randomized, controlled trial. CMAJ. In press.

9. Burback D, Molnar FJ, St. John P, Man-Son-Hing M. Key methodological features of randomized controlled trials of Alzheimer's disease therapy: minimal clinically important difference, sample size, and trial duration. Dement Geriatr Cogn Disord. 1999;10:534-40.

10. Hsiung GYR, Sadovnick AD, Feldman H. Apolipoprotein E e4 genotype as a risk factor for cognitive decline and dementia: data from the Canadian Study of Health and Aging. CMAJ. 2004; 171:863-7.

11. Gauthier S. The benefits of apolipoprotein E e4 screening to research. CMAJ. 2004;171:881.

12. Poirier J. Apolipoprotein E4, cholinergic integrity, and the pharmacogenetics of Alzheimer's disease. J Psychiatry Neurosci. 1999;24:147-153

13. Sano M, Ernesto C, Thomas RG, Klauber MR, Schafer K, Grundman M, et al. A controlled trial of selegiline, alphatocopherol, or both as treatment for Alzheimer's disease. The Alzheimer's Disease Cooperative Study. N Engl J Med. 1997;336:1216-22.

14. AD2000 Collaborative Group. Long-term donepezil treatment in 565 patients with Alzheimer's disease (AD2000): randomized, double-blind trial. Lancet. 2004;363:2105-15.

15. Leber P. Slowing the progression of Alzheimer disease: methodologic issues. Alzheimer Dis Assoc Disord. 1997; 11 Suppl 5:S10-21.
16. Whitehouse PJ, Kittner B, Roessner M, Rossor M, Sano M, Thal L, et al. Clinical trial designs for demonstrating disease-coursealtering effects in dementia. Alzheimer Dis Assoc Disord. 1998;12:281-94.

17. Echt DS, Liebson PR, Mitchell LB, Peters RW, Obias-Manno D, Barker $\mathrm{AH}$, et al. Mortality and morbidity in patients receiving encainide, flecainide, or placebo. The Cardiac Arrhythmia Suppression Trial. N Engl J Med. 1991;324:781-8.

18. Ellenberg SS. Analytical, practical, and regulatory issues in prevention studies. Stat Med. 2004;23:297-303.

19. Kryscio RJ, Mendiondo MS, Schmitt FA, Markesbery WR. Designing a large prevention trial: statistical issues. Stat Med. 2004;23:285-96.

20. Winblad B, Engedal K, Soininen H, Verhey F, Waldemar G, Wetterholm AL, et al. A 1-year randomized, placebo-controlled study of donepezil in patients with mild to moderate AD. Neurology. 2001;57:489-95.

21. Mohs RC, Doody RS, Morris JC, Ieni JR, Rogers SL, Perdomo CA, et al. A 1-year, placebo-controlled preservation of function survival study of donepezil in AD patients. Neurology. 2001;57:481-8

22. Forette F, Seux ML, Staessen JA, Thijs L, Babarskiene MR, Babeanu S, et al. The prevention of dementia with antihypertensive treatment: new evidence from the Systolic Hypertension in Europe (Syst-Eur) study. Arch Intern Med. 2002;162:2046-52.

23. Schneider LS, Olin JT, Lyness SA, Chui HC. Eligibility of Alzheimer's disease clinic patients for clinical trials. J Am Geriatr Soc. 1997:45:923-8.

24. Kokmen E, Ozsarfati Y, Beard CM, O’Brien PC, Rocca WA. Impact of referral bias on clinical and epidemiological studies of Alzheimer's disease. J Clin Epidemiol. 1996;49:79-83.

25. Treves TA, Verchovsky R, Klimovitsky S, Korczyn AD. Recruitment rate to drug trials for dementia of the Alzheimer type. Alzheimer Dis Assoc Disord. 2000;14:209-11.

26. Gill SS, Bronskill SE, Mamdani M, Sykora K, Li P, Shulman KI, et al. Representation of patients with dementia in clinical trials of donepezil. Can J Clin Pharmacol. 2004;11:e274-85.

27. Winblad B, Poritis N. Memantine in severe dementia: results of the 9M-Best study (benefit and efficacy in severely demented patients during treatment with memantine). Int $\mathrm{J}$ Geriatr Psychiatry. 1999;14:135-46.

28. Fox E, Curt GA, Balis FM. Clinical trial design for target-based therapy. Oncologist. 2002;7:401-9.

29. Fillit HM, O'Connell AW, Brown WM, Altstiel LD, Anand R, Collins K, et al. Barriers to drug discovery and development for Alzheimer's disease. Alzheimer Dis Assoc Disord. 2002; 16 Suppl 1:S1-8.

30. Altstiel LD. Barriers to Alzheimer's disease drug discovery and development in the biotechnology industry. Alzheimer Dis Assoc Disord. 2002;16 Suppl 1:S29-32.

31. Simon RM, Steinberg SM, Hamilton M, Hildesheim A, Khleif S, Kwak LW, et al. Clinical trial design for the early clinical development of therapeutic cancer vaccines. J Clin Oncol. 2001;19:1848-54.

32. Mathews PM, Nixon RA. Setback for an Alzheimer's disease vaccine: lessons learned. Neurology. 2003;61:7-8. 